\title{
Problems and prospects of utilizing canal banks to enhance the built-environment in Colombo
}

\author{
Ranjith Perera
}

\begin{abstract}
Waterfronts are assets that enhance the quality of built-environment in urban areas. They are used as public and recreational spaces in many cities around the world. However, cities and towns in Sri Lanka most often turn their back to water bodies. Colombo has environmental assets in the form of a sea front, a lake and a canal network, yet not much attempt has been made to utilize their potential to enhance the quality of environment of the city until recent times. The lake is being rehabilitated while the canal network has already been rehabilitated under externally funded projects. It is observed that the rehabilitated canal network is fast falling back to its previous state of stagnation and pollution due to non-utilization of improved canals and banks. This paper focuses attention on possible strategies to sustain their improved environmental quality in order to enhance the built-environment of the city.
\end{abstract}

\section{Introduction}

Cities located along rivers and canals is a spatial phenomenon in many countries in the world. However, virtually living on these water bodies themselves is a specific phenomenon seen in Southeast Asian cities. For example $23 \%$ of houses in Ho Chi Minh City's canal bank settlements are completely located over the canals' water surface while $62 \%$ of houses are partly located on land and partly located on canals. In the canal bank settlements of Bangkok, the figures are lower at $15 \%$ and $47 \%$ respectively due to the frequent use of canals for transportation purposes (Dong, 2002:54). Although waterways are not used for settlements to that extent in South Asian countries, this region also demonstrate an urban development pattern highly associated with rivers and canals. Most cities and towns in South Asia are founded in association with sea, rivers and other water bodies.

Water-based settlements date back to the earliest periods of civilization in the Asian region. People settled along water bodies not only for the ease of obtaining water for agricultural purposes but also for the ease of movement. Rivers and canals have often served as major lifelines to these settlements for the purposes of obtaining food, consumer goods and service necessary for their sustenance. As a response to this significance the buildings located along the banks usually faced the water bodies. However, with the rapid progress in land transport technologies the importance of waterways as arteries of settlements has gradually diminished. Roads have taken over the function of water bodies as the primary means of getting access to buildings and serving transport needs. With these new developments waterways have been neglected and became backyards of buildings. Additionally, they have become dumping grounds for solid and liquid waste disposed from numerous industries, commercial establishments and houses located along them. More over, with rapid urbanization, banks of water bodies have become popular squatting grounds for migrants. who could not find better footholds in cities. They have conveniently encroached river and canal reservations for settlement since these are public properties in most instances. These encroachments as well as dumping of wastes by households, industries and other establishments have caused poor environmental conditions in many water bodies over the period of time.

After having had a long period of similar fate, Colombo's canals have at last acquired a new look by undergoing "an expensive facelift". The silted, polluted and stagnating pools of water of yesteryear are no more. The shanties that crowded the banks, making the canals an eyesore are no longer there. What prevails now are wide expanses of water that actually flow, neatly constructed banks and upgraded houses lining the canal reservations. However, there are signs that after having a new life for a short period the canals are gradually falling back to dis-use due to insufficient maintenance, monitoring, pollution and utilization. Unless strategies are identified to sustain the improved quality of canal environment, the colossal amount of funds spent on rehabilitating Colombo's canal system will be wasted.

This paper focuses on the strategies of sustaining the environmental quality of long abused and recently rehabilitated canals in Colombo, as urban water fronts to enhance the built-environment of the city.

\section{Need for Canal Rehabilitation and Maintenance}

The commonest environmental problem in a canal ecosystem is the deterioration of water quality due to the presence of faecal matter, toxic substances, garbage and other organisms. This is associated with foul smells and unpleasant appearance of dark and murky water. Thesey easily become breeding grounds for disease 
carrying parasites and rodents. As a result public health of those who live close to canals and use water therein are threatened by water borne diseases. Dumping of solid waste and encroachment by shanties result silting and narrowing of canals. The combined effect of these disturbances is poor drainage capacity of canals and recurrent floods during the rainy season.

The socio-economic as well as environmental hazards posed by polluted, silted and encroached canals necessitate rehabilitation of them to safeguard cities and their people from calamities. Especially, periodic rehabilitation of canals is a major flood control measure in most water-based cities since it is very vital to maintain the capacity and flow of canals in order to protect cities against flood hazards.

However, in most cities in developing countries canal rehabilitation and maintenance are tedious tasks since canal banks are encroached by people for various activities including settlement. Therefore, canal rehabilitation projects often include strategies to rehabilitate and improve the quality of environment in canal bank settlements if encroachers are not completely evicted and relocated. In addition to the usual rehabilitation strategies such as dredging of canals, clearing of reservations and consolidation of banks, the housing condition of people living along the banks are also improved in order to prevent them from encroaching and polluting the canals again. Special measures are taken to prevent domestic wastewater, sewage and solid waste from entering the canals. Accordingly canal bank rehabilitation is a complex type of project involving civil engineering, environmental management, social development, and urban design strategies. However, if the improved qualities of settlements as well as canals are not sustained in the long run implementation of such strategies may be futile exercises. Therefore, it is very vital that the improved quality of built environment in settlements and condition of canals are sustained in order to reduce the vulnerability of cities to floods and other environmental calamities.

This paper examines the above need with reference to the Greater Colombo Flood Control and Environment Improvement Project, which was implemented in 1990s. It argues a case for the need of sustaining the environmental quality of rehabilitated canals through nonconventional methods of maintenance.

\section{Greater Colombo Canal System}

The City of Colombo is located in the flood plain of Kelani River. Most of the land presently occupied by the city had been marshy land reclaimed for urban development over a period of nearly 500 years. Presently there is an extensive canal cum lake system, which drains storm water to the river as well as to the ocean (see fig.1). This system is partly natural and partly man-made. The
Dutch who occupied Colombo in the $17^{\text {th }} \& 18^{\text {th }}$ Century have improved this system to use it for inland transport purposes and to protect the city from floods. There had been an extensive inland water transport system running from North to South, cutting across the major town centers located on the western coast of Sri Lanka. Thus, the canals have formed a continuous link of waterways between sea or river ports and the remote sections of territory under the Dutch. There had been settlements along Dutch built canals as still seen in some parts of the northern suburbs of Colombo. However, houses built on stilts over the water surface of canals as seen in Southeast Asian cities are not common in Sri Lanka.

Colombo's canals had been very vibrant, as their counterparts in Bangkok. However, canals in Colombo had been very dormant since roads grew in importance in serving transport needs, while canals in Bangkok still contribute to the life and economy of the city, despite far superior development of land transport networks and modes in the city.

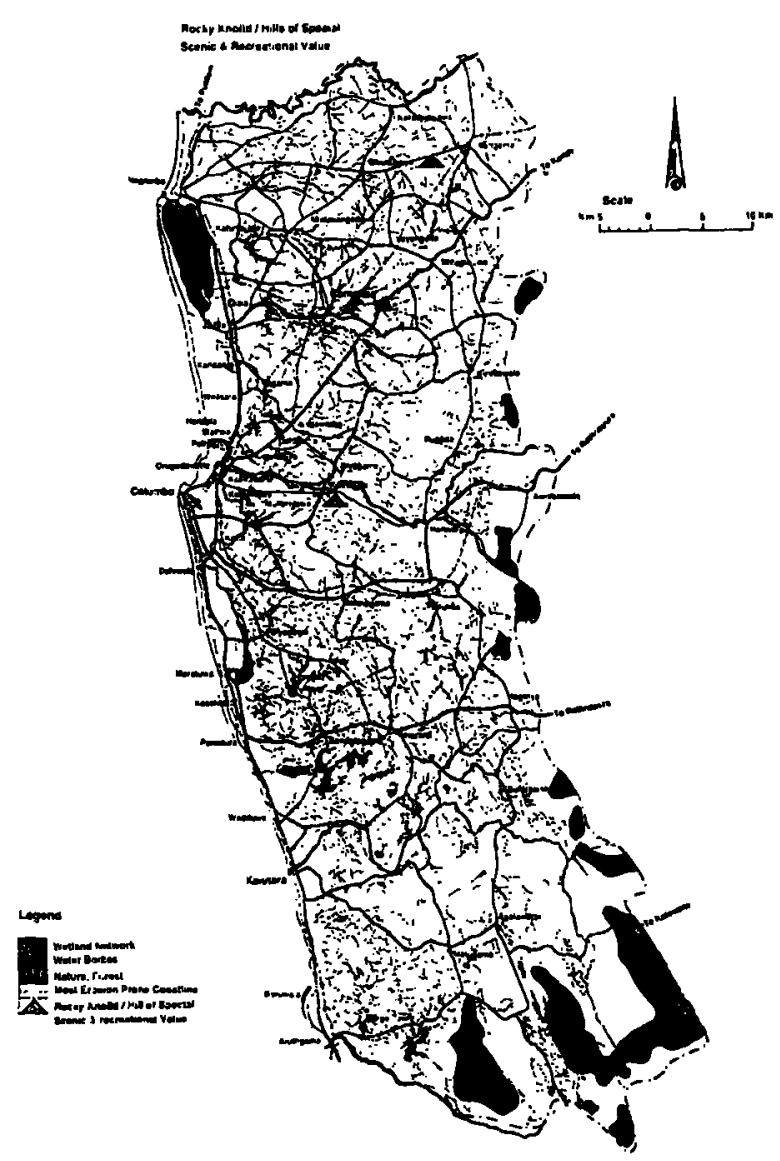

Fig.1: Greater Colombo canal system

(source: UDA, 1998)

The canal bank shanty settlements in Colombo are a more recent phenomenon dating back to the early $20^{\text {th }}$ century. People who migrated to the city in search of jobs have first settled on marshy land in the periphery of the city. These shanty settlements have gradually spread to the canal banks. Eventually most of the canals have been encroached by squatters making them 
narrower and shallower. This has reduced the capacity of canal system to handle storm water during a flood event.

\subsection{Flooding in Colombo}

Before the implementation of the Greater Colombo Flood Control and Environment Improvement Project, many parts of Colombo City were subject to frequent flooding due to insufficient capacity of the canal system. The canals were partly undersized, badly silted and not maintained to the necessary extent. On the other hand marshy land have been reclaimed and developed most often in an unplanned manner without due regard to local and general drainage patterns. These unplanned reclamations have reduced the flood storage capacity within the wetland system as well as the canal system.

Frequent flooding of many parts of the city has been adversely affecting the economic activities and public health. UDA identifies that "without prejudice to other serious problems, flooding is the most critical environmental problem in the city, directly affecting almost every other environmental and development issue" (UDA, 1998:81). After experiencing the heaviest rainfall of $495 \mathrm{~mm} / 24 \mathrm{hr}$. and a devastating flood that followed on June 4 , 1992, which paralyzed the city and its suburbs for a week, the authorities strongly felt that a complete rehabilitation of the canal system as an urgent need. The initial investigations have revealed that the canal system is not only undersized but also heavily polluted due to discharging of wastewater, sewage and garbage by canal bank dwellers as well as industries. Although squatters were identified as the cause for undersizing, some industries were identified as the main culprits of water pollution. In order to address the dual problem of flooding and environmental pollution, the Greater Colombo Flood Control and Environment Improvement Project was launched in 1993.

\subsection{Greater Colombo Flood Control and Environment Improvement, Project}

The main objective of this project was to rehabilitate the existing canal system ( $43 \mathrm{~km}$ ) spreading over the Greater Colombo area together with the construction of a few new canals $(10 \mathrm{~km})$ in order to alleviate the flooding in a catchment area of about $80 \mathrm{sq} . \mathrm{km}$. This area includes the areas of Colombo Municipal Council and three other adjacent urban local authority areas viz., Kotte Municipal Council, Dehiwela-Mt. Lavinia Municipal Council and Kollonnawa Pradesheeya Sabha (UDA, 1998:146). The project was formulated to improve the environment adjacent to the canals including upgrading or relocation of about 7400 housing units that existed on canal banks.

The main project activities include,

1. De-silting, dredging and widening of the canals

2. De-toxication of canal beds by removing toxic sludge

3. Flushing the polluted water in the canals and refill with fresh storm water

4. Stabilization and consolidation of banks with gabion walls, retaining walls, landscaped slopes or other methods

5. Re-establishment of statutory canal reservation lines and access roads by removing unauthorized structures on the banks, and

6. Resettlement of people evicted for clearing the banks in altemative sites or upgrade on site (with land tenure) for those who do not seriously obstruct the canal reservations.

Sri Lanka Land Reclamation and Development Corporation (SLLRDC) was responsible for the implementation of this project, which was funded by the Overseas Economic Corporation Fund (OECF) of Japan. The OECF granted Rs. 4500 million (US \$ 110 million) loan, which at that time was the largest provided by the Japanese Govemment for a single development project in Sri Lanka. Phase I of the project was completed in 1997 utilizing this fund and Phase II, which addresses the storm water drainage aspects of built-up areas is scheduled to becompleted in 2002

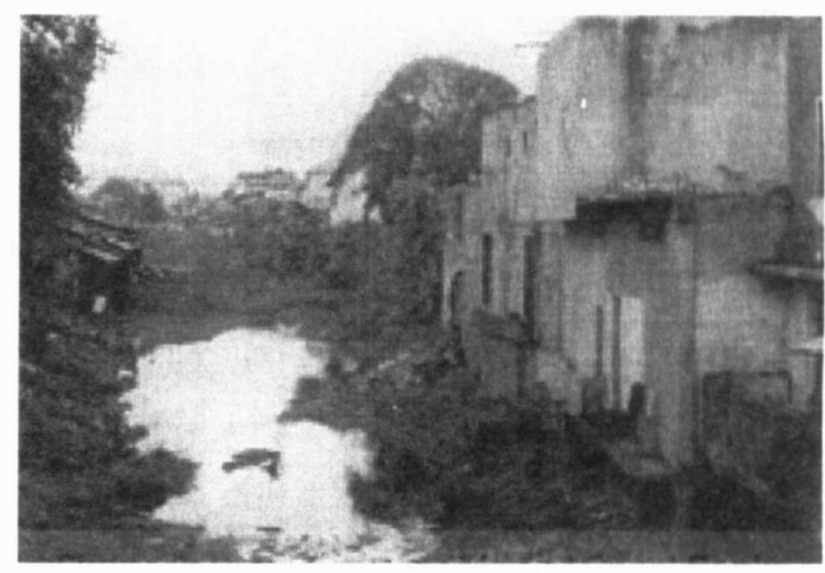

Figure 2: Previous Condition of Canal Banks (photo credits: Herath, 1996)

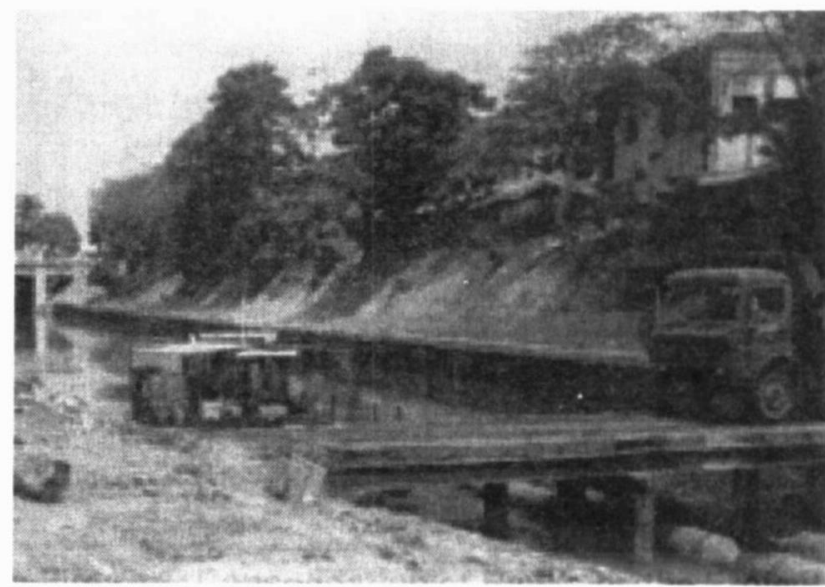

Figure 3: Consolidation of Banks by the Project 


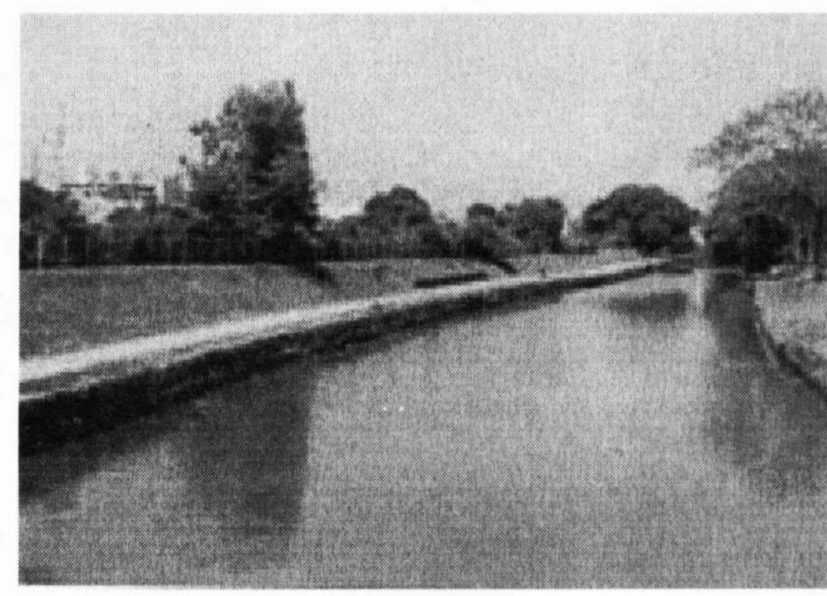

Plate 4: A Rehabilitated Canal (photo credit: Bandaranayake, 2000)

\section{Problems of sustainability}

Although many stakeholders including SLLRDC believe that the project has largely relieved the city of serious floods, the UDA is skeptical about the sustainability of the project.

"Existing flood control projects address mainly the City of Colombo and its immediate environs, a small part of the overall region. Current project solutions are mainly based on obsolete technology that is mechanically complex and high maintenance engineering which ignores many socio-economic realities and is not sustainable in the long run" (UDA, 1998:81).

UDA's skepticism was proven correct when the city experienced a major flood on April 20-21, 1999. The newspapers reported that it was as bad as the flood of 1992 although the rainfall was much less at $280 \mathrm{~mm} / 24$ hrs. "Many of the roads in Colombo and the suburbs laid deep under water and countless number of homes were inundated" (Fernando, 1999). The media attributed this flood to several reasons.

1. Filling of marshy lands in an unplanned manner to meet the high demand for urban land;

2. Lack of equipment, organizational capacity and funding for effective maintenance of rehabilitated canal system;

3. Continued encroachment of canal banks and construction of unauthorized structures with the backing of local politicians;

4. Continued dumping of garbage to the canals by unscrupulous people.

However, the SLLRDC disputes these claims by insisting that rehabilitated canals have the capacity to cope-up with regular floods when the Phase II of the project to improve the drainage system in built-up areas is completed in 2002. Yet the crux of the matter is that rehabilitated canals are fast falling back to their previous status due to lapses in maintenance and monitoring. Therefore, there is an urgent need to ensure sustainability of rehabilitated canals in order to prevent calamities of similar intensity.
If the canals are not maintained regularly they will fall back to the previous status in no time. The signs are that the reverse process has already started in areas where low-income settlements are prevalent. It is a common sight to see garbage floating in some stretches of rehabilitated canals. Foul smells are also emanating in some areas. Although SLLRDC has sealed-off most inlets bringing sewage and wastewater into canals, garbage continues to flow-in due to the inefficiency of the solid waste management system in the city as well as the indifferent attitude of people living in the vicinity of canals.

It is obvious that there are still pollutants flowing into waterways. In the absence of sufficient capacity to maintain the canal system regularly, other strategies must be explored to maintain the quality of environment in canals and canal banks. In other words, now with the threat of serious floods minimized, the authorities and the citizens should look into the strategies to maintain the canals and their environments by utilizing them for other purposes. Proper utilization of canals and canal banks will be an indirect method to discourage unscrupulous people from harming the canal system and its environment once again.

\section{Strategies to Sustain the Quality of Environment}

A research study by Herath (1996) has looked into the possible strategies to develop canal waterfronts as public spaces. Although the urban design strategies that have been identified are desirable to improve the quality of built-environment along canal banks, the more important needs are indirect strategies to maintain the canals system through participation of citizens, civil societies, NGOs, private entrepreneurs and government institutions. These may include,

1. Revenue generating activities such as boat transport services for commuters, and especially wetland tours or leisure trips for tourists and holidaymakers, and restaurants/boutiques both of the floating type and stationary ones on the canal banks.

2. Recreational activities such as rowing in the canals and jogging/walking on the canal banks

3. Landscaping canal banks with the participation of canal bank residents, private entrepreneurs and local authority

4. Pollution control and encroachment prevention through community participation and environmental awareness building

The SLLRDC has looked into the prospects of promoting commercial activities and civic activities by developing canal banks as urban waterfronts. It has also looked into the prospect of public and private participation in maintaining designated stretches of canal banks. 


\subsection{Commercial Activities}

In 1997, SLLRDC called for expression of interest from the private sector to operate commercial activities in canals and canal banks by way of newspaper advertisements. The SLLRDC claims that it is pleased with the response and interest shown by the private sector in investing in the new-look canals. It also claims that few private sector investors with foreign collaborators who are presently engaged in similar activities in cities such as Bangkok and Singapore have shown interest. The advertisements have garnered about 50 applications from private enterprises as well as civic societies and private individuals. The obvious change in looks would have prompted the interest shown by the private parties on investing in the canals and their future.

In offering some selected stretches of canals the SLLRDC expected the investors to conform to environmental standards set by them in all commercial activities. Land was to be leased for canal bank activities and permission to be given to use the waterways on the basis of a licensing fee. Since canals and canal reservations are under the jurisdiction of the Irrigation Department of Sri Lanka, it was questionable whether SLLRDC can lease canals and canal banks and give license for private entrepreneurs to engage in commercial ventures. The SLLRDC was only the executing agency of the Flood Protection and Environment Improvement Project.

Despite the initial show of interest, the reality is that not a single commercial activity has been established by the end of 2002. Among the activities proposed, most were restaurants of floating or stationary type. There were few proposals for boutiques, sports clubs and recreational activities. The breakdown of proposals is given below.

\begin{tabular}{|l|c|}
\hline Proposed Activity & No. of Applications \\
\hline Restaurants on land & 28 \\
\hline Floating restaurants & 4 \\
\hline Sports clubs & 3 \\
\hline Boutiques/kiosks & 12 \\
\hline Commuter transport & - \\
\hline Joy rides by boat & 2 \\
\hline Fitness park & 2 \\
\hline Total & $\mathbf{5 1}$ \\
\hline
\end{tabular}

Table1: Show of interest by private entrepreneurs for activities along canals

The failure to generate sufficient enthusiasm among entrepreneurs and the general public can be attributed to the lack of a water-based entertainment culture in the city. Unlike Bangkok and Singapore where waterways are much celebrated spaces in urban life, people in Colombo show a lukewarm attitude to even larger waterbodies such as Beira Lake and Diyawanna Lake in the city. The former located in the heart of the city, is largely unnoticed since it is mostly shielded by warehouses and various other buildings. Although there had been several urban renewal proposals for the lake's surrounding, once again nothing has materialized yet, except a project to rehabilitate the lake.

Even before the emergence of security threats at public places people disregarded the Beira Lake due to its unpleasant environmental conditions. In contrast, the beaches in Colombo always attract crowds seeking leisure spaces. Therefore, a well-organized promotion campaign is needed to attract people to canal banks and make commercial activities successful. Without that the authorities will not be able to generate sufficient funds for maintaining the canals. A World Bank sponsored canal rehabilitation project in Ho Chi Minh City (Saigon) has demonstrated that improved environmental qualities can be sustained by promoting commercial, recreational and public activities along canal banks despite poor quality of water in the canals (see Fig.5). However, a research study conducted by Bandaranayake (2000) on the viability of utilizing Colombo's canal system indicate that weak integration of canals with the rest of the urban fabric as a major draw back in introducing sustainable activities along canal banks

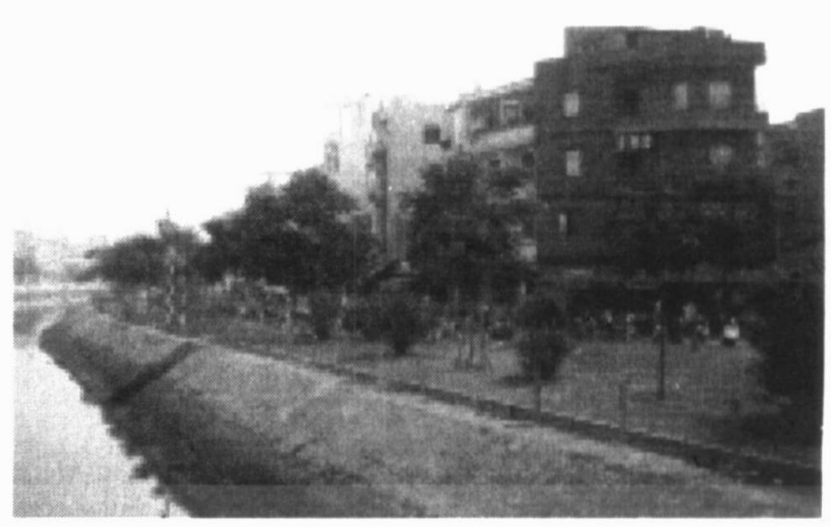

Figure 5: A rehabilitated Canal Bank in Saigon

\subsection{Use of canals for commuter transport and recreational activities}

Transport activities will be useful to aerate water in the canals and control the growth of Water Hyacinth. However, the above table shows that there is not much demand for investing in transport activities in the canals. Only a limited number of entrepreneurs wish to use the canals for leisure activities. Even if there is interest such activities may not be possible without overcoming the following problems.

1. Depth of water in some canals is insufficient during the dry season for passenger boats.

2. There is insufficient headroom underneath some road bridges.

3. Tie beams of some bridge foundations do not allow boats to pass through when the water level is low. 
4. There are no piers for passengers to embark and Too much garbage, especially plastic bags deposited on the canal beds interfere with boat engines.

5. There are not many origin and destination points of commuters along canals.

6. Unbearable smell of water at certain canal stretches may discourage people from traveling along the canals.

Due to these problems, Dharmapala et al. (1997) concludes that only leisure rides to experience the Heen Ela marsh, Kotte Lake and Diyawanna Lake will be feasible on a commercial basis, yet security concerns may not make it viable particularly in the Diyawanna Lake. Citing the success of nature trails and leisure boat rides operated by the Central Environmental Authority in a conserved wetland area north of Colombo (Dharmapala, et al., 1997) they view that boat rides along the loop consisting of Heen Ela, Kotte Ela, Kotte Lake and Kolonnawa Ela might be an attraction for both local and foreign tourists (see Fig.1).

Dharmapala et al. (1997) also views that commuter transportation may not be feasible due to the technical and environmental problems cited above. Significant saving of travel time would be achieved in the few routes they have studied if water level in the canals is satisfactory. Yet the study also expresses skepticism on social acceptance of boat as an alternative transport mode due to the poor quality of water, bad odour and security concerns. Boat as a public transport mode is very rare in Sri Lanka. Therefore, making it popular in a canal system, which is not so pleasant and not so conveniently located in relation to transport nodal points, is not a very feasible idea.

Despite this non-feasibility Dharmapala et al. (1997) finds that leisure riding and recreational sports such as rowing may be practical in some canals. Other activities such as walking and jogging along the canal banks are practical only along the stretches, which cut across public roads. Since most canal banks are still back yards without much connection to public spaces, only people who live along them can get access to the canal banks. However, it is seen that canal banks, which run parallel to existing and newly constructed access roads are becoming popular public spaces. Some communities living along these stretches have even taken own initiatives to landscape the canal banks for social gatherings. This is observed in new settlements in the vicinity of Royal Park condominium. It is definitely a boon for the self-maintenance of canals.

\subsection{Public-private partnership in maintaining canal banks}

In the city consultation meetings held under the City Development Strategies (CDS) Program of UNCHS
(Habitat) and World Bank, it was revealed that private enterprises, particularly the local banks are keen to fund city beautification projects to promote their own brand images (CMC, 2000). Although this is an opportunity to attract private investments to beautify canal banks they show interest only to more visible public spaces. Since most stretches of the canals run through residential areas, which are not so visible from main roads, it is somewhat difficult to attract private sector investments to improve the environmental condition of canal banks. In other words, lack of visibility of the canal banks is a major draw back in attracting investment. Therefore, the communities living along those stretches have a higher responsibility in maintaining the quality of their living environment.

\subsection{Community participation in urban environmental management}

It is disappointing to note that people have a very indifferent attitude towards the canals. This is evidenced by the presence of garbage in canals. Irrespective of the type of communities garbage is present in the waterways. However, it is observed that garbage and foul smell are more in the areas where low-income families reside. According to the SLLRDC, both lowincome and high-income families are engaged in NIMBYing. They choose canal as the easiest place to throw garbage. Therefore it is necessary to launch an environmental awareness-building program among communities living along Colombo's Canals. The recently introduced "Green Star" labeling system by the Colombo Municipal Council is an innovative step forward. Under this system 5 different stars are awarded to a premise depending on environmental performance. Since this is deeply attached to one's pride and dignity people tend to be more conscious about the quality of their living environment. This system can be extended to include communities and neighbourhoods where they can be awarded higher accolades for good environmental performance. It should be in the interest of people to keep the canals clean since the quality of their living environment would depend on how good the waterways look.

\subsection{Conclusions}

It is clear that none of the usual strategies practiced in other cities for self-maintenance of urban canals work in Colombo. The main reason is non-acceptance of canals as attractive waterfronts by public. Since the attitude of people towards canals has not changed from backyards to front-yards SLLRDC finds it difficult to transform the rehabilitated canals and caral banks to attractive public spaces. The SLLRDC alone cannot make the change of attitude without the co-operation of local authorities, private enterprises, community organizations and the individual citizens. While the SLLRDC has the responsibility to improve and maintain 
the quality of water and canal environment, other stakeholders need to partner with SLLRDC to ut the improved environments into public uses so as to ensure that they will not become backyards again.

The importance of civic mindedness and co-operation of the public is stressed in this regard. Much money has been spent on expanding and rehabilitating the canals. If the public continues to either encroach or use them as garbage dumping grounds, no purpose will be served. More over, local politicians should not encourage encroachers for selfish reasons. The authorities find it difficult to take actions against offenders when they have political patronage. Since selfmaintaining activities are not so viable along the canals, a concerted effort by the public as well as those in authorities is needed to ensure that the canals are kept unobstructed and clean in order to enhance the quality of environment in the city.

\section{References}

Bandaranayake, C. (2000). Viability of Utilizing Urban Canal Systems for Socio-economic Activities in the City of Colombo, Unpublished M.Sc. (Architecture) Dissertation Submitted to the University of Moratuwa.

CMC (2000). City Development Strategy, Colombo, Colombo Municipal Council.

Dharmapala, S. et al. (1997). Feasibility Study of a Commuter Transport Service in the Canal System of Colombo, Unpublished B.Sc. Eng.
Project Report Submitted to the University of Moratuwa, Sri Lanka.

Dissanayake, T. (1997). “Colombo's Canals Coming to Life", Colombo: The Sunday Times, 31" August 1997.

Dong, P.Q. (2002). Urban Environmental Management Policies to Improve the Living Condition in Canal Bank Settlements in Ho Chi Minh City, Unpublished M.Sc. Thesis submitted to the Asian Institute of Technology, Bangkok, Thailand.

Fernando, H. (1999). "Floods: When will we cope", The Sunday Times, $9^{\text {th }}$ May 1999.

Herath, S. (1996). Utilizing. Canal Banks as Urban Water Fronts to Enhance the Built-Environment in Colombo City, Unpublished M.Sc.

(Architecture) Dissertation Submitted to the University of Moratuwa.

UDA, (1998). Colombo Metropolitan Regional Structure Plan, Colombo: Urban Development Authority

Acknowledgement:

This paper is based on research work conducted by the author with Sujeewa Herath, Chandima Bandaranayake and Sandaruwan Dharmapala of University of Moratuwa and Pham Quang Dong of Asian Institute of Technology. The author gratefully acknowledges their contribution of ideas for the original research work. 